\title{
O DIAGNÓSTICO DE DEFICIÊNCIA ANDROGÊNICA DO ENVELHECIMENTO MASCULINO E OS (DES)CAMINHOS DO DESEJO SEXUAL MASCULINO
}

\author{
Lucas Tramontano \\ Jane Araujo Russo
}

\begin{abstract}
RESUMO
Este artigo visa discutir o diagnóstico de Deficiência Androgênica do Envelhecimento Masculino (DAEM) e as controvérsias e disputas que o acompanham, à luz da "remedicalização" da sexualidade. A análise parte de entrevistas realizadas com médicos urologistas e endocrinologistas. As diferentes abordagens entre essas especialidades elucidam concepções divergentes de corpo e sexualidade presentes no pensamento biomédico, e a disputa por hegemonia no campo científico. Através da comparação entre os significados atribuídos à DAEM e a outra disfunção sexual masculina, a Disfunção Erétil (DE), pretendemos refletir sobre as dificuldades inerentes à redução biológica da sexualidade e à reiteração de normas de gênero no discurso médico sobre o corpo e a sexualidade masculina.
\end{abstract}

Palavras-chave: DAEM. Andropausa. Medicalização. Sexualidade masculina.

\footnotetext{
${ }^{1}$ Professor substituto do Instituto de Estudos em Saúde Coletiva, da Universidade Federal do Rio de Janeiro e Doutorando no Instituto de Medicina Social, da Universidade do Estado do Rio de Janeiro, Brasil, lucas.tramontano@gmail.com

${ }^{2}$ Professora do Programa de Pós-Graduação em Saúde Coletiva do Instituto de Medicina Social, da Universidade do Estado do Rio de Janeiro, Brasil, jane.russo@gmail.com
} 


\section{THE DIAGNOSIS OF ANDROGENIC DEFICIENCY OF THE AGING MALE AND THE PATHS OF MALE SEXUAL DESIRE ABSTRACT}

This article discusses the diagnosis of Androgenic Deficiency of the Aging Male (ADAM) and the controversies and disputes over it, based on the re-medicalization of sexuality. The analysis is based on interviews with urologists and endocrinologists, and the different approaches of these two medical specialties elucidate divergent conceptions of body and sexuality present in the biomedical knowledge, and the struggle for hegemony in the scientific field. By comparing the meanings attributed to ADAM and to another male sexual dysfunction, the Erectile Dysfunction (ED), we intend to reflect about the difficulties inherent in the biological reduction of sexuality and the reiteration of gender norms in the medical discourse concerning the male body and sexuality.

Keywords: ADAM. Andropause. Medicalization. Male sexuality.

\section{INTRODUÇÃO}

comparação entre os significados atribuídos à Deficiência Androgênica
do Envelhecimento Masculino (DAEM) e a outra disfunção sexual
masculina, a Disfunção Erétil (DE), permite-nos vislumbrar tanto os percalços no pleno estabelecimento da DAEM numa perspectiva biologicista da sexualidade, quanto as convenções presentes no discurso médico sobre o corpo e a sexualidade masculina.

Para Conrad (2007), o final do século XX assiste a uma difusão de explicações médicas para todo tipo de angústia. Assim, nos últimos 30 anos, pelo menos, a medicina passou a considerar como problemas de saúde uma série de condições e comportamentos que até então não eram percebidos dessa forma. A medicalização seria, portanto, um processo que transforma "problemas da vida", não-médicos, em doenças passíveis de tratamento, transformando o que era considerado "desvio" (crime, imoralidade, pecado) em patologia; e processos comuns da vida em problemas médicos. Outras explicações possíveis sobre 0 corpo perdem sentido e são substituídas por uma visão mecanicista, na qual o 
papel da medicina é trocar ou aprimorar peças e mecanismos do corpo-máquina que não funcionam como deveriam, ou de acordo com o desejado ${ }^{3}$.

Essa redução biológica das condições que afligem o sujeito tem consequências singulares no estudo científico da sexualidade. A Sexologia se estabelece na virada do século XIX para o XX como a ciência que se dedica a descrever e explicar a sexualidade humana, sob uma ótica médica. Os pressupostos que definem o que será considerado um problema, porém, mudam de acordo com o contexto histórico e o lugar que o sexo ocupa na sociedade. Russo et al (2009) analisam essas transformações, destacando três momentoschave, descritos pelos autores como três "ondas" da Sexologia. A primeira, na Alemanha da virada do século XIX para o XX, é focada nas "perversões sexuais"; a segunda, em torno dos anos 1960/70, nos Estados Unidos, traz uma preocupação com a sexualidade "normal" do casal heterossexual; já a terceira onda, sobre a qual nos debruçamos nesse artigo, é protagonizada pelos urologistas em parceria com a indústria farmacêutica no final do século XX e se volta para a sexualidade masculina, inaugurando o termo Medicina Sexual, em substituição à Sexologia (RUSSO, 2013). A DAEM seria um dos carros-chefes dessa terceira onda.

A partir dos anos 1980, impulsionada principalmente pelas pesquisas sobre impotência sexual, a Urologia, em parceria com a indústria farmacêutica, ganhou amplo terreno com o lançamento, em 1998, do citrato de sildenafil, o Viagra, marcando 0 início da terceira onda. A visão mais psicologizante do pós-guerra, simbolizada pelas propostas de Williams Masters e Virginia Johnson, passa a conviver com uma vertente médica. Nesse momento, de fato, acompanhando uma mudança na medicina em geral, se estabelece o que Russo (2013) caracteriza como uma re-medicalização da sexualidade.

Nesse contexto, cresce a importância de um diagnóstico preciso, associado à disponibilidade de um tratamento farmacológico específico. Não à toa, é nesse mesmo período que a indústria farmacêutica se destaca entre os principais atores, com ampla influência sobre os rumos da pesquisa científica e da prática clínica

\footnotetext{
${ }^{3} 0$ conceito de medicalização está em intensa discussão no campo científico atual. Reformulações e atualizações são propostas por diferentes autores, seja no sentido de expandir o conceito ou de superá-lo. Entre várias posições possíveis, destacamos a "biomedicalização" de Clarke et al (2003), as considerações sobre a biopolítica e as "políticas da vida" trazidas por Nikolas Rose (2013). Além disso, outros conceitos dão destaque a características mais específicas do processo de medicalização, como "farmacologização" (pharmaceuticalization), discutida por Fox e Ward (2008) ou "sanitarização" (bealthicization), proposta por Hislop e Arber (2013). Optamos pela utilização de "medicalização" conforme Conrad, acrescida das elaborações de Rose, por considerálas mais condizentes com o objeto.
} 
(ANGELL, 2007; DUMIT, 2012; ROSE, 2013). Meika Loe (2001), pensando sobre 0 uso do Viagra, descreve uma "farmacologização do sexo", na qual os produtos farmacêuticos passam a ser entendidos como "drogas de estilo de vida" servem mais para aperfeiçoar um corpo que não funciona como deveria (ou fazêlo funcionar ainda melhor) do que propriamente curar uma doença.

Entretanto, dialogando com Rose (2013) e Dumit (2012), a definição do corpo como saudável ou doente é bastante complicada na atualidade. A concepção de saúde perde consistência na medida em que, a partir das noções articuladas de risco e suscetibilidade, é sempre possível descobrir uma possibilidade futura de doença ou disfunção mesmo no sujeito inteiramente assintomático. A "doença oculta” está sempre demandando comportamentos preventivos, vigilância, novos e mais sofisticados exames. 0 cuidado de si exigido em tais circunstâncias faz com que a distinção entre tratamento e aprimoramento seja cada vez mais tênue.

As agências reguladoras, entretanto, para aprovar a comercialização de uma droga, exigem provas de que a mesma seja indicada para alguma patologia. A indústria farmacêutica tende, por isso, a ressignificar determinadas condições como patologias que demandam um tratamento farmacológico. Em alguns casos, essa passagem é bem sucedida, como aconteceu com a dificuldade de ereção a partir da construção da DE; no entanto, no caso da DAEM, o processo não foi tão simples, nem tão completo.

\section{DELIMITANDO O CAMPO E A METODOLOGIA}

Revisitamos, neste trabalho, entrevistas semi-estruturadas realizadas para obtenção do mestrado em Saúde Coletiva no Instituto de Medicina Social da UERJ (TRAMONTANO, 2012). 0 principal objetivo desse estudo era investigar como 0 discurso médico relacionava a DAEM e a testosterona com a medicalização da sexualidade masculina, a manutenção de uma certa ideia de masculinidade e a invenção de novas perspectivas de envelhecimento. Os sujeitos da pesquisa foram urologistas e endocrinologistas que lidam com DAEM tanto na prática clínica quanto na pesquisa acadêmica. Entre os endocrinologistas, foram entrevistados dois homens, um em Florianópolis e outro no Rio de Janeiro; e uma mulher,

\footnotetext{
${ }^{4}$ Para Meika Loe (2001, p. 120), "lifestyle drugs generally promise to enhance a consumers life in some way. Allergy medications, hair growth medications, anti-depressants, and birth control pills may be considered lifestyle drugs by many insurers and practitioners in the sense that they are optional in terms of health". Sobre drogas de estilo de vida, ver também Azize (2002) e Nucci (2012).
} 
também do Rio de Janeiro. Já entre os urologistas, foram entrevistados apenas homens ${ }^{5}$, sendo um do Ceará, outro do Rio Grande do Sul, um de São Paulo e um do Rio de Janeiro. Todas/os assinaram um Termo de Consentimento Livre e Esclarecido $0^{6}$. A pesquisa foi submetida e aprovada no Comitê de Ética em Pesquisa do Instituto de Medicina Social da UERJ.

A escolha por essas especialidades médicas se deu a partir de análise prévia do campo da medicina sexual, que as apontava como as mais envolvidas no diagnóstico de DAEM. Essa observação concordava com pesquisas realizadas a partir dos currículos na Plataforma Lattes utilizando os marcadores "DAEM" e "andropausa". Cruzando os resultados, chegamos a uma lista de dez urologistas e cinco endocrinologistas, já demonstrando a prevalência dos primeiros no campo. Como nem todos os selecionados responderam às tentativas de contato, entrevistamos quatro urologistas e três endocrinologistas.

Consideramos interessante sair do eixo Rio de Janeiro-São Paulo, acreditando na possibilidade de diferenças regionais na construção da DAEM, que acabaram não se comprovando. Os entrevistados de outras regiões do país estavam bem alinhados com o discurso dos médicos do Sudeste. Aliás, Rio de Janeiro e São Paulo podem ser considerados o epicentro da discussão em torno da DAEM, sendo os locais com a maior concentração de profissionais dedicados ao tema. Buscou-se fazer a entrevista pessoalmente ou pelo telefone. De toda forma, já no convite enviado por correio eletrônico, abria-se a possibilidade de outros meios de contato; no fim, as entrevistas foram feitas também através de comunicadores instantâneos (Skype e MSN) e por email.

0 roteiro das entrevistas se dividiu em dois grandes grupos de perguntas: um relativo à definição de DAEM e outro, sobre a terapia de reposição hormonal. Um terceiro tema atravessava esses dois, referindo-se às disputas entre as duas especialidades médicas, e às diferenças nas abordagens dos problemas colocados, que encobriam diferentes concepções de corpo e doença. As questões acerca da definição de DAEM incluíram perguntas sobre os diferentes nomes da doença e sobre o diagnóstico em si, subdividido em sintomas e exames laboratoriais e indagando a centralidade do sexo nas queixas do paciente. Já em relação ao tratamento, as perguntas versavam sobre a disponibilidade e 0 acesso ao medicamento, as diferenças entre as formas farmacêuticas, as contraindicações e

\footnotetext{
${ }^{5}$ É raro encontrar mulheres nessa especialidade, não aparecendo nenhuma nas seleções feitas para a pesquisa, nem indicadas por outros colegas.

${ }^{6}$ Todos os trechos de entrevistas aqui citados serão apresentados em itálico, para diferenciar de citações da literatura, e os nomes das/os entrevistadas/os são fictícios para garantir o anonimato.
} 
as consequências para a masculinidade ${ }^{7}$ da deficiência de testosterona. Gênero e envelhecimento foram mantidos como eixos transversais. Este artigo focaliza 0 primeiro grupo de perguntas.

\section{DEFININDO DAEM}

Mas afinal o que é DAEM? As diferentes respostas a essa simples pergunta já demonstram a fragilidade do diagnóstico e a dificuldade de consenso que 0 envolve. De maneira concisa, podemos descrevê-la como a reformulação de uma antiga condição, nem sempre explicada em termos médicos, que seria a "andropausa". Considerada por muito tempo um "mito" mais do que uma "verdade científica", a andropausa já foi definida de diferentes formas e por diferentes profissionais, tendo como fio condutor uma preocupação (médica) com o declínio físico e sexual do homem no envelhecer.

Marshall \& Katz (2002, p. 45-47) apontam que já no século XVI diversas teorias tentavam explicar esse decaimento. Porém, uma relação clara entre a diminuição do desejo sexual e o envelhecimento masculino só seria feita no século XIX, com a ideia de "doença do climatério". . Assim, o primeiro a definir a condição como uma patologia teria sido Sir Henry Halford, médico do rei George III da Inglaterra, em 1813, e já para o médico inglês, havia uma dificuldade em definir os limites da patologia e do envelhecimento normal, um problema que ainda acompanha a DAEM 9 . 0 período que marca o início da doença também já era confuso no século XIX, variando dos 50 aos 75 anos de idade. Contudo,

\footnotetext{
${ }^{7}$ Nesse trabalho, assim como no presente artigo, ao falarmos em masculinidade, entendemos 0 termo dentro da perspectiva relacional característica dos estudos de gênero. Entre os médicos entrevistados, contudo, masculinidade se refere exclusivamente à masculinidade hegemônica conforme pensada por Connel (2005), excluindo-se outras acepções concorrentes do termo e negligenciando vivências de gênero mais fluidas. Para uma discussão mais profunda sobre masculinidade, ver Connel (2005) e Tramontano (2012).

${ }^{8}$ Porém, Fernandez \& Acosta (2008), dois endocrinologistas espanhóis, afirmam que já no século IX e X, médicos árabes descrevem um declínio da atividade sexual em homens aos 63 anos, sendo, segundo os autores, a referência médica mais antiga ao que seria, séculos depois, chamado de andropausa. Ressalto, contudo, que a medicina desse período não definia estados de doença em diagnósticos precisos, essa sendo uma característica bem mais recente do campo. Sobre a necessidade de diagnósticos precisos na medicina moderna, ver Foucault (2008) e Rosenberg (2002).

${ }^{9}$ A diferença entre um envelhecimento "normal" e um patológico é central nas discussões que envolvem a DAEM, porém, foge ao escopo desse artigo. Para uma análise focada nesse ponto, ver Tramontano (2014).
} 
destacam os autores, o declínio sexual da velhice no século XIX era considerado decorrente do "excesso libidinoso" ao longo da vida, e a atividade sexual na velhice, sem fins reprodutivos, era recriminada moralmente. Sendo assim, não havia grandes esforços para tratar o climatério.

No século $\mathrm{XX}$, a preocupação com 0 envelhecimento recebe maior destaque, e com a teoria hormonal do corpo, que apresenta os hormônios sexuais como essências do sexo/gênero, o climatério ganha outros contornos. A síntese industrial de testosterona e sua possível comercialização nos anos 1930 traz a "menopausa masculina" de volta à cena, sob o nome de "climatério viril" (OUDSHOORN, 1994, p. 101). A partir daí, a disfunção sexual se tornou seu principal sintoma que, no entanto, esbarrava ainda na questão moral da (a)sexualidade dos idosos.

A situação começou a mudar nos anos 1960, quando a atividade sexual depois do período reprodutivo se tornou mais aceitável (MARSHALL, 2007; ROHDEN, 2011). Porém, a andropausa só ganhou força, de fato, nos anos 1990, com as pesquisas sobre DE e o foco da medicina sexual no corpo masculino. Segundo Bonaccorsi (2001, p.124), endocrinologista brasileiro e responsável pela principal revisão bibliográfica no país sobre DAEM, foi apenas em 1994, num congresso da Sociedade Austríaca de Andrologia, que se admitiu a existência da andropausa, que passa a ser denominada Partial Androgen Deficiency of the Aging Male (PADAM). A partir desse momento, diversas reuniões propõem novas nomenclaturas, focando num ou noutro aspecto da patologia, não havendo uma escolha inequívoca (FERNANDES \& ACOSTA, 2008). Mas, o termo que se tornou relativamente consensual foi Deficiência ou Distúrbio Androgênico do Envelhecimento Masculino - DAEM.

No momento da pesquisa, era esse o nome oficialmente utilizado pela Sociedade Brasileira de Urologia (SBU), e DAEM já vem aparecendo assim nomeada na mídia leiga (ROHDEN, 2011), apesar de não ganhar muita popularidade, uma vez que o termo "andropausa" continua sendo largamente utilizado no senso comum, e mesmo em alguns espaços acadêmicos e publicações oficiais, conforme descrito informalmente por um dos endocrinologistas entrevistados. Para o urologista Edgar, a definição do nome é menos importante do que a garantia de um bom diálogo na clínica: $O$ que eu acho relevante é que você consiga estabelecer uma forma compreensiva de contato com o paciente, que o faça entender do que se trata a referida situação 
clínica $^{10}$. Para a endocrinologista Roberta, DAEM ou hipogonadismo masculino tardio são nomes, assim, muito grandes, não têm o mesmo impacto que andropausa, então, meio que pegou andropausa. Não tem um nome assim, melhor.

Por outro lado, também houve relatos bastante incisivos na defesa do termo DAEM em detrimento de andropausa, que, para o urologista Luis, só é ainda utilizado por quem quer abreviar a referência a ele, por quem pretende fazer uso sensacionalista do termo e por quem não se incomoda em utilizar a norma culta da linguagem. 0 rechaço ao termo "andropausa" vem no sentido de diferenciar a DAEM da menopausa feminina. Segundo esses médicos, nas mulheres há, de fato, uma pausa na produção hormonal dos ovários, ao passo que os testículos nunca cessam sua produção, apenas a diminuem gradualmente ao longo dos anos, num processo acelerado pela DAEM. Além disso, andropausa traz a ideia de esta corresponder a um processo "natural", pelo qual todos os homens passariam, como acontece com a menopausa. Em contrapartida, a DAEM é considerada uma deficiência ou distúrbio, ou seja, enquadrada como uma patologia.

Controvérsias à parte, a definição se refere a uma patologia que acomete homens a partir da meia-idade (localizada em torno dos 40/50 anos), quando a taxa hormonal de testosterona começa a diminuir gradativamente, causando uma série de sintomas

(...) principalmente relacionados à diminuição da libido (desejo sexual), alteração do desempenho e da frequência sexual, cansaço físico e mental, irritabilidade, perda de massa muscular, aumento de gordura da região abdominal, perda de pelos, alteração da textura da pele, que fica mais fina, e em alguns casos, osteoporose (www.movimentosaudemasculina.com.br/o-que-e-andropausa) ${ }^{11}$.

Segundo essa definição, confirmada pelos especialistas informantes, a diminuição da taxa de testosterona é considerada um processo "natural" do envelhecimento, mas pode ocorrer precoce e mais intensamente em alguns

\footnotetext{
${ }^{10}$ A flexibilização dos termos técnicos no sentido de favorecer um diálogo na clínica através de "uma linguagem acessível para os pacientes" também foi observada por Azize (2002, p. 102).

${ }^{11}$ Essa página foi acessada a partir do site oficial da Sociedade Brasileira de Urologia (SBU), www.sbu.org.br, em 06 de janeiro de 2012.
} 
homens, que recebem o diagnóstico de DAEM e para os quais é prescrito um tratamento de reposição hormonal de testosterona ${ }^{12}$.

\section{NÃO DÓI, NÃO ARDE, NÃO COÇA}

As entrevistas foram iniciadas perguntando quais são as principais queixas que levam homens, a partir dos 40 anos, a procurar o consultório do entrevistado. As respostas invariavelmente apontavam problemas relativos à atividade/performance sexual: alteração da libido, disfunção erétil, alterações no orgasmo e alteração na ejaculação (Edgar, urologista). Mas, em todas as entrevistas, os médicos apontavam como principal queixa a queda ou falta de libido, considerada por eles o principal sintoma de DAEM ${ }^{13}$.

Entre os pacientes, não há, normalmente, desconfiança acerca de uma deficiência hormonal, ou uma busca pela reposição, como acontece com as mulheres nos consultórios ginecológicos. Chega-se ao diagnóstico de DAEM a partir da desconfiança do médico de que o problema de ereção ou libido decorra da baixa hormonal. Ainda que existam casos de homens mais jovens (em torno dos 40 anos) que procuram 0 médico se queixando de diminuição do tônus muscular ou de uma sensação de cansaço generalizada, tais situações são bastante minoritárias (apenas um urologista e um endocrinologista afirmaram ouvir tais queixas). Além disso, os pacientes não associam outros sintomas a uma disfunção sexual. Para o endocrinologista Rodrigo, essa dificuldade de percepção dos sintomas seria comum a outras doenças mais "silenciosas":

O ruim é você tratar doenças que não doem inicialmente, não dói, não arde, não coça, né, diabetes, colesterol... Enquanto não está sentindo nada, o paciente não se queixa. Agora, quando ele acha que age sobre uma parte importante dele do corpo [...] ele sente melhor, sim (Rodrigo, endocrinologista).

\footnotetext{
${ }^{12}$ Apesar de haver uma convergência nesse sentido, os informantes concordam por caminhos conflitantes. Diferentes reuniões de consenso são citadas (uma européia, uma norte-americana, uma brasileira; da Endocrine Society, da SBU, da Sociedade Brasileira de Endocrinologia e Metabologia - SBEM), e os médicos consideram mais válidas (ou a única relevante) aquelas nas quais eles próprios estiveram presentes. Já em relação ao tratamento ser a reposição hormonal de testosterona, não há questionamentos.

${ }^{13}$ Para os entrevistados, "libido" é sinônimo de "desejo sexual", e os termos são intercambiáveis.
} 
0 interessante nessa fala é a ideia de que a DAEM age sobre uma "parte importante" do corpo, que seria o pênis. Em várias entrevistas, principalmente com urologistas, os médicos afirmaram que a maioria de seus pacientes hipogonádicos chega ao consultório buscando "uma receita de Viagra", de forma análoga ao observado por Azize (2002, p. 73) em sua pesquisa com usuários de Viagra. Observa-se, portanto, um entrecruzamento das categorias diagnósticas, com ênfase na dificuldade de ereção, apesar de esta não ser uma consequência direta da deficiência de testosterona.

Porém, o diagnóstico sempre é clínico e laboratorial, lembra-nos o endocrinologista Alberto, sendo que tanto Roberta (endocrinologista), quanto José (urologista) destacam a necessidade de serem feitas mais de uma dosagem (o ideal seriam três consecutivas) para confirmar a deficiência, já que outras doenças podem variar temporariamente os níveis do hormônio. Nesse ponto, entramos num terreno pantanoso, uma vez que não há um teste que meça diretamente a testosterona sérica, ou seja, a testosterona livre na corrente sanguínea. E, mesmo quando essa dificuldade é driblada, como será discutido abaixo, o valor limite, abaixo do qual se considera que o indivíduo está hipogonádico, não é consensual.

\section{MEDindo A TESTOSTERONA}

Medir a testosterona que circula na corrente sanguínea não é uma tarefa simples. Na ausência de um teste confiável para mensurar os níveis séricos do hormônio, recorre-se a um cálculo indireto, cujo primeiro parâmetro é a dosagem de testosterona total. Mede-se também a $\mathrm{SHBG}^{14}$ e a albumina, proteínas às quais os hormônios sexuais se ligam. Utilizando-se a Fórmula de Vermeulen, chega-se finalmente ao valor da testosterona livre calculada ${ }^{15}$. Ainda que existam outros métodos, como a dosagem do padrão-ouro ou por radioimunoensaio, estes são caros ou falhos, sendo pouco usados pelos entrevistados, e mesmo em outros

\footnotetext{
${ }^{14}$ SHBG é a sigla para Sexual Hormone-Binding Globuline, ou globulina ligadora de hormônios sexuais.

${ }^{15}$ A Fórmula de Vermeulen é um cálculo complexo para determinar indiretamente a testosterona biodisponível. A testosterona circula na corrente sanguínea ligada não-especificamente à albumina e especificamente à SHBG, e, em menor porcentagem, circula livre, não-ligada. A fração biodisponível, ou seja, a que está disponível para exercer os efeitos fisiológicos do hormônio, seria a fração livre mais a fração ligada à albumina. Porém, essa biodisponibilidade seria apenas parcial, já que, a nível celular, pode ocorrer tanto a dissociação do complexo testosterona-SHBG, como a conversão de pró-hormônios inativos em moléculas ativas do hormônio, disponibilizando mais testosterona. Apesar disso, a fração biodisponível é considerada a mais fiel para medir os níveis de hormônio no plasma sanguíneo em situações clínicas.
} 
contextos internacionais (BONACCORSI, 2001). A preferência por um teste em detrimento de outro, e a especificidade de um teste para uma determinada substância são essenciais para a legitimidade de uma "descoberta" científica (LATOUR \& WOOLGAR, 1997).

Confiando ou não nos testes disponíveis, uma baixa dosagem de testosterona total chama a atenção dos entrevistados e os faz recorrer aos outros testes. Todos concordam que há uma diminuição não patológica dos níveis de testosterona a partir de certa idade, que deveria ser em torno de $1 \%$ ao ano, embora os parâmetros não sejam os mesmos para todos os médicos. Para iniciar a reposição, a taxa seria testosterona total menor de 250 [ng/dL], ou com sintomas evidentes e testosterona entre 250 e 350 (Felipe, urologista). Porém, para o endocrinologista Alberto, o paciente que tem uma testosterona total abaixo de 300ng/dL merece uma avaliação mais adequada, assim como para 0 endocrinologista Rodrigo e para o urologista Edgar, que vai um pouco além:

niveis de testosterona total abaixo de 300ng, acho que é um excelente candidato para a reposição hormonal. Quando ele tiver valores de testosterona acima de 400, eu fico muito em dúvida em categorizar ele com um hipogonadismo. Entre 300 e 400 de testosterona total, e se os sintomas forem relevantes, a reposição deve ser contemplada (Edgar, urologista).

A avaliação desse ponto crítico pode não ser tão óbvia, ganhando contornos mais subjetivos na clínica, como vemos no relato abaixo:

essa queda pode ser muito relativa; se você já tem um paciente [...] há muitos anos, e ele tem [...] uma dosagem de testosterona de $550 \mathrm{ng} / \mathrm{dL}[. .$.$] esse indivíduo com a queixa, alguns anos depois,$ queixas típicas de hipogonadismo, ou, eventualmente, de depressão, você tem uma [...] dosagem hormonal de 330, por exemplo, sendo que o normal seria talvez entre 300 e 800ng. Então, muito provavelmente, a queda desse indivíduo foi muito maior do que a queda esperada no envelhecimento, ou num processo natural. Nesse caso sim, apesar dele estar dentro [...] dos parâmetros considerados normais, mas, especificamente para esse indivíduo, é provável que ele tenha uma queda hormonal. Então, nesse caso, você, conbecendo o paciente, você está autorizado a fazer o diagnóstico então de um hipogonadismo muito provável... como se diz, assim, 
proporcional ou relativo a ele mesmo, não em termos absolutos (José, urologista).

Na revisão de Bonaccorsi (2001), porém, o valor de corte deveria ser de 350ng/dL. Aqui percebemos, em consonância com Dumit (2012), a tendência atual da biomedicina de "baixar" os valores limítrofes das patologias, como ocorreu com 0 índice de massa corporal, a hipertensão arterial ou a glicemia. Essa manobra possibilita a inclusão de mais indivíduos como doentes, além de criar uma etapa intermediária entre o normal e o patológico, uma espécie de "prédoença". Assim, condições ou estados que poderão desencadear (ou não) o desenvolvimento de uma patologia, ou que são sintomas de outras doenças, passam a ser tratados como um agravo de saúde em si. Porém, no caso da DAEM, o resultado laboratorial confirmando a deficiência hormonal não é suficiente, havendo ainda a necessidade de um relato mais ou menos estruturado dos sintomas pelo paciente para confirmar o diagnóstico. Pode ser que isso decorra da pouca confiabilidade nos exames laboratoriais, sem grande significado para 0 estabelecimento da doença, entretanto, é mais uma característica diferencial da DAEM.

\section{CORPOS, CLÍNICAS E UM TRATAMENTO}

Em todas as entrevistas realizadas apareceram diferenças entre os médicos das duas especialidades indagadas. Geralmente quando os pacientes vão ao urologista, já têm a suspeita de uma disfunção sexual, e esse costuma ser 0 primeiro profissional que procuram ${ }^{16}$. Já os pacientes que vão ao endocrinologista são muitas vezes encaminhados por outros médicos que desconfiam de um problema hormonal. Também é comum que outras alterações endócrinas ou seus tratamentos (destaque para o diabetes) causem a deficiência hormonal, identificada e tratada pelo endocrinologista. Portanto, no discurso desses profissionais há muitas referências a outras doenças, enquanto os urologistas falam direta e exclusivamente das disfunções sexuais.

Quando perguntados sobre qual especialidade médica estaria mais apta a diagnosticar e tratar a DAEM, a disputa aparece de forma mais clara. Por mais que a tendência fosse cada um privilegiar sua especialidade, vários médicos afirmavam

\footnotetext{
16 Nesse ponto, observamos novamente uma continuidade entre 0 discurso dos médicos entrevistados em nossa pesquisa e os achados de Azize (2002), que observa que "o diagnóstico que leva ao uso de Viagra [...] não começa necessariamente no consultório médico" (AZIZE, 2002, p.68-9).
} 
que normalmente o uro e o endócrino (Felipe, urologista) são os mais indicados. Contudo, a diplomacia não foi muito longe no caso de José (urologista), que argumenta que a endocrinologia também estaria apta porque é uma especialidade que eventualmente, entende até mais de bormônios do que o próprio urologista, mas há um porém que privilegia o urologista.

o grande problema que eu vejo no endocrinologista de fazer o tratamento, ou de qualquer outro médico, é que ele não tem essa conviç̧ão de controle da próstata como o urologista tem. É por isso que eu acho, bonestamente, que essa reposição precisa ser feita ou numa associação do endócrino com o urologista ou então, se for só por uma pessoa, que seja pelo urologista (José, urologista).

De toda forma, o diagnóstico de DAEM não é assim tão simples, causando uma confusão tão grande entre até os próprios especialistas que lidam com isso que se a gente passa isso para um clínico geral, isso daí fica até mais complicado (Roberta, endocrinologista). 0 profissional deve acompanhar as inovações e descobertas nessa área, o que, para 0 urologista Edgar, pode ser difícil: qualquer médico tem condições de fazer isso, desde que ele se interesse pelo assunto, mas, na prática, muitos indivíduos não fazem isso porque não encontram ainda uma segurança, ou seja, ainda são pouco esclarecidos para esse tópico.

Uma diferença entre as duas especialidades é sutilmente colocada. A urologia cuidaria da forma anatômica, cirúrgica da patologia (Rodrigo, endocrinologista), enquanto a clínica seria feita pelos endocrinologistas. Para 0 endocrinologista Alberto,

a urologia é uma especialidade eminentemente cirúrgica [...] é um perfil diferente do médico clínico. Então, o melhor profissional pra tratar isso é aquele que [...] gosta de ter paciência no consultório para conversar com o paciente, para examinar o paciente. [...] Então, não é que o urologista não possa tratar, pode sim! Porém, tem que ser aquele urologista que tem um perfil clínico.

A diferença clínica/cirurgia parece bem importante nas disputas internas da medicina, e não é à toa que só foi citada pelos endocrinologistas, já que a cirurgia demorou a ter a mesma relevância que a clínica. Nos primórdios da medicina moderna, médicos eram os estudiosos do corpo e das doenças; manipular corpos 
de fato era uma tarefa menor, relegada a indivíduos sem formação nem status social. Nesse período,

(...) os cirurgiões são tratados como trabalhadores manuais. Sua atividade está no plano das artes mecânicas. Nas universidades, os professores leigos são mantidos afastados e não se ensina a cirurgia. Em Paris, em 1350, a Faculdade de Medicina obriga os bacharéis a jurarem jamais proceder a uma cirurgia (ROHDEN, 2009, p. 102).

Os cirurgiões demoraram a ser aceitos nas associações médicas, e um resquício desse estigma parece ainda se manter. Na era pós-Viagra, porém, os urologistas conseguiram "sair do Centro Cirúrgico" e se gabaritar como clínicos através das disfunções sexuais masculinas. Todavia, os endocrinologistas fazem questão de lembrar que eles ainda são "cirurgiões", com pouca experiência clínica, como vemos no relato de Rodrigo (endocrinologista):

Se [o urologista] não se interessar muito pela parte clínica, a parte de reposição, ele vai encaminhar para a gente. A partir do momento que for necessária uma prótese, uma doença funcional do órgão dele, a gente retorna para o urologista para fazer esse tratamento.

Espera-se que haja uma disputa, e mesmo um certo desdém, entre especialidades médicas no que tange à legitimidade para tratar certas doenças e para postular novas teorias médicas. Essas disputas fazem parte da dinâmica da ciência e de seus jogos políticos. Analisando a construção dos fatos científicos, Latour e Woolgar (1997) apontam como um "enunciado" científico, ao ser aceito como um fato, dispensa explicações sobre os caminhos que levaram à sua postulação. Os pesquisadores estão assim envolvidos numa rede de influência mútua, na qual a capacidade de estabelecer um enunciado como um fato (e sua reiteração a cada nova citação) depende muito do prestígio do lugar ocupado pelo pesquisador nessa rede, desacreditando outros enunciados concorrentes.

Na Medicina Sexual, quem ocupa o lugar de maior destaque na rede é a urologia. Lembramos que a hoje chamada Medicina Sexual teve início com os estudos sobre impotência, levados a cabo pelos urologistas ainda nos anos 1980 (RUSSO, 2013; GIAMI, 2009). Antes do surgimento dos medicamentos para DE, o tratamento mais utilizado para os casos de impotência (associados ou não à idade) era a colocação cirúrgica de próteses penianas. Além disso, é importante 
ressaltar a tendência a focalizar a sexualidade masculina e seus problemas no funcionamento do órgão sexual. Essa tendência impõe-se a partir de concepções arraigadas acerca da diferença de gênero, em que a sexualidade feminina é concebida como mais difusa e "complexa", abarcando a mulher como um todo, ao passo que a sexualidade masculina é mais "simples" e tende a se resumir no funcionamento do pênis, concebido de forma mecânica.

0 lançamento posterior do Viagra voltado exclusivamente para a produção de uma "ereção firme o suficiente para permitir a penetração", com 0 consequente lançamento do diagnóstico de DE para substituir a antiga impotência, confirma tal tendência. Assim, cresce a legitimidade dos urologistas na disputa por uma área específica da medicina até então pouco explorada, destacando-se como uma autoridade científica privilegiada no campo. Com isso, sua posição na hierarquia se inverte.

Por outro lado, a rede na qual a DAEM se encontra inclui também endocrinologistas, introduzindo uma outra visão sobre o corpo. A endocrinologia, talvez por ser mais claramente clínica, talvez por pressupostos inerentes ao seu objeto de estudo, traz uma visão mais integrada do paciente. Ao que parece, a visão do corpo da urologia é mais fragmentada, enquanto a endocrinologia descreve um corpo mais íntegro. Esse aparente "holismo orgânico" parece ser em parte decorrente da ideia de eixo neuroendócrino: a metáfora mais adequada para explicar o corpo, para os endocrinologistas, seria um sistema de informações. Em contrapartida, para os urologistas, o corpo-máquina seria a melhor metáfora. Portanto, a abordagem dos problemas, filtrada por essas concepções do corpo, é significativamente diferente para as duas especialidades. Por consequência, a formulação das hipóteses e o acompanhamento terapêutico também tendem a ser. Uma comprovação disso está no fato de que todos os endocrinologistas ouvidos se referem a diversas outras condições que podem influenciar temporariamente os níveis hormonais, relativizando a centralidade da disfunção sexual num quadro patológico mais amplo, num movimento oposto à ênfase na atividade sexual apresentada pelos urologistas.

Não à toa, é num espaço da endocrinologia que 0 próprio estatuto patológico da DAEM foi questionado. Nas palavras de Alberto (endocrinologista): 
Diga-se de passagem, essa semana [a DAEM] foi contestada nos Estados Unidos no Congresso da Endocrine Society ${ }^{17}$. O Handelsman, pesquisador australiano, (...) questionou o que o Massachusetts Male Aging Study tinha mostrado, que a partir dos 40 anos temos um declínio progressivo independente de doença. Ele mostrou que o vínculo com doenças parece que é mais evidente do que com a idade. O que ele quis dizer? Apesar do número de pacientes estudados por ele não ser tão grande, a queda hormonal foi mais evidente entre as pessoas com alguma co-morbidade diabetes, obesidade - do que particularmente numa população sadia $^{18}$.

Roberta e Rodrigo, os outros endocrinologistas entrevistados, fazem coro a Alberto (ou a Handelsman). Entretanto, isso parece não ser levado em conta pelos urologistas, que não citam o trabalho do pesquisador australiano, e, quando perguntados sobre a hipótese defendida por ele, simplesmente a desacreditam ${ }^{19}$.

Não se trata, contudo, de privilegiar uma ou outra abordagem; no fim das contas, mantém-se a descrição do corpo como uma entidade autárquica e fechada em si mesma (LeBRETON, 2011). Para além disso, é preciso refletir até onde importa essa suposta diferença uma vez que 0 tratamento será o mesmo: a reposição de testosterona. $\mathrm{E}$, se a testosterona é capaz de reverter o quadro sintomático de DAEM, possíveis divergências nas definições de corpo serão

\footnotetext{
${ }^{17}$ O congresso citado foi o END0 2011: The Endocrine Society 93 ${ }^{\text {rd }}$ Annual Meeting, ocorrido em Boston, Massachusetts, de 04-07 de junho de 2011.

${ }^{18} 0$ Massachusetts Male Aging Study (MMAS) é a principal referência citada para justificar a existência de DAEM, como aparece na revisão de Bonaccorsi (2001). É a partir dos dados do MMAS, acrescidos obviamente de pesquisas mais recentes, que o autor faz seu levantamento, no qual se estabelecem a sintomatologia, os exames laboratoriais necessários para o diagnóstico, 0 tratamento e suas contraindicações, além de uma mínima discussão sobre o estatuto patológico do DAEM frente ao processo considerado normal de envelhecimento. 0 artigo de Bonaccorsi podia ser citado em numerosas passagens ao longo desse artigo, haja vista que o discurso dos entrevistados é uma repetição mais ou menos sistematizada dessa revisão. Ironicamente, Bonaccorsi é endocrinologista, mas os entrevistados que transformam suas hipóteses e questionamentos em verdades absolutas e irrevogáveis são os urologistas.

${ }^{19}$ Mudanças recentes no campo parecem alterar um pouco essa questão. No $21^{\circ}$ Congresso da World Association for Sexual Health - WAS, ocorrido em setembro de 2013 em Porto Alegre-RS, urologistas de destaque no campo brasileiro utilizam bem menos o nome DAEM, dissolvido num diagnóstico mais amplo de "Desejo Hipoativo", que pode ser masculino ou feminino. Quando perguntamos se DAEM seria um termo ultrapassado, esses pesquisadores afirmaram que não, ainda se mantém o uso do termo, porém mais num âmbito nacional do que internacional.
} 
eclipsadas pela eficácia do tratamento medicamentoso, como o Viagra fez no caso da $\mathrm{DE}^{20}$.

\section{CONSIDERAÇÕES FINAIS}

Todas essas contradições transformam a DAEM num diagnóstico dúbio e, em última instância, num diagnóstico fraco. Uma justificativa possível para essa fragilidade passa pelo fato de que o diagnóstico entra em conflito com ideias estabelecidas no senso comum acerca do corpo e da sexualidade masculinas. Segundo Ludwick Fleck (2010), a construção de um fato científico depende da existência de certos elementos prévios na cultura que possibilitem sua percepção daquela forma específica. Mais do que isso, algo só poderá ser percebido se estiver de acordo com 0 estilo de pensamento de um determinado grupo, se sua existência já estiver de alguma forma consolidada, mesmo que rudimentarmente, no que 0 autor polonês chama de "protoideias".

Assim, encontra-se subjacente no estilo de pensamento da medicina sexual brasileira uma protoideia da sexualidade masculina como algo direto e objetivo, atributos considerados característicos da masculinidade. Uma demonstração gráfica da força dessa concepção aparece numa figura divulgada em congressos de Sexologia, na qual se descreve a sexualidade feminina como um painel de avião, composto por dezenas de botões, telas informativas e sinais luminosos; em contraste, a sexualidade masculina aparece na figura como um único botão de on/off, conforme observado por Russo et al. (2011, anexo D).

Essa protoideia da objetividade masculina se coaduna com a abordagem dada à DE. Nesse caso, a patologia passou a ser descrita praticamente como um "problema hidráulico" - basta fazer com que o sangue entre nos "canos" certos e não saia. Os medicamentos para a DE, nessa perspectiva, são claramente um magical bullet, ou seja, são tecnologias pontuais que solucionam um problema bastante específico (LOE, 2001). Por outro lado, uma vez que a ação dos hormônios é descrita como ampla, mediando diversos mecanismos fisiológicos, a DAEM se torna muito mais difusa; sua definição como uma deficiência hormonal torna impossível eleger uma intervenção farmacológica tão seletiva como no caso do Viagra e seus similares.

\footnotetext{
${ }^{20}$ Para uma discussão mais profunda de como, a partir do lançamento do Viagra, surge uma afirmação da eficácia do medicamento independente da etiologia da doença, o que leva a um apagamento das diferentes concepções de corpo e do processo saúde/doença acionadas por diferentes abordagens terapêuticas, ver Giami (2009).
} 
Esse caráter difuso da DAEM pode ser observado ainda num outro nível. Além da pouca seletividade do hormônio, que acaba por mediar diversas outras respostas fisiológicas que não precisavam necessariamente ser alteradas, o efeito desejado da reposição é também de difícil localização. Enquanto a DE se responsabiliza pela ereção apenas, a DAEM se propõe a uma normalização/ampliação do desejo sexual, que não está exatamente localizado em lugar algum (ou mesmo em vários) do fragmentado corpo biomédico. Sendo assim, sua redução a um mecanismo biológico único para então propor um efetivo "conserto" farmacológico se torna uma difícil (se possível) tarefa.

Cabe ainda refletir sobre as consequências simbólicas da medicalização do próprio desejo sexual. $\mathrm{Na} \mathrm{DE}$, o homem quer fazer sexo, mas seu corpo o impede; na DAEM, ele perde a vontade de fazer sexo, o que contradiz uma das principais expectativas sociais da masculinidade hegemônica: a disponibilidade irrestrita para 0 sexo. Assim, é possível afirmar que as contradições entre o paradigma biomédico atual $\mathrm{e}$ as protoideias concernentes à masculinidade $\mathrm{e}$ ao funcionamento do corpo e da sexualidade masculinas são suficientes para justificar a fragilidade do diagnóstico da DAEM, ou, ao menos, sua pouca adesão popular.

\section{REFERÊNCIAS}

ANGELL, Marcia. A verdade sobre os laboratórios farmacêuticos $1^{a}$ edição. Rio de Janeiro: Record, 2007.

AZIZE, Rogerio. A química da qualidade de vida: um olhar antropológico sobre o uso de medicamentos e saúde em classes médias urbanas brasileiras. Março de 2002. 118 f. Dissertação (Mestrado em Antropologia Social) - Departamento de Antropologia, Universidade Federal de Santa Catarina, Florianópolis. 2002.

BONACCORSI, Antonio Carlos. Andropausa: insuficiência parcial androgênica do homem idoso. Uma revisão. Arquivos Brasileiros de Endocrinologia Metabólica, v. 2, n. 45,2001, p. $45-57$.

CLARKE, Adele; SHIM, Janet; MAM0, Laura; FOSKET, Jennifer Ruth; FISHMAN, Jennifer. Biomedicalization: technoscientific transformations of health, illness and US biomedicine. American Sociological Review, v. 68, 2003, p. 161-194.

CONRAD, Peter. The Medicalization of Society. Baltimore: The Johns Hopkins University Press, 2007. 
CONNEL, R. W. Masculinities. Second Edition. Berkeley and Los Angeles: University of California Press, 2005.

DUMIT, Joseph. Drugs for Life. How pharmaceutical companies define our bealth. Durham and London: Duke University Press, 2012.

FERNANDEZ, A. \& ACOSTA, L. Documento básico de consenso sobre el síndrome de hipogonadismo de inicio tardío. Endocrinol. Nutr., v.1, n. 55, 2008, p.5-28.

FLECK, Ludwick. Gênese e Desenvolvimento de um Fato Científico. Belo Horizonte: Fabrecatum, 2010.

FOUCAULT, Michel. o Nascimento do Hospital. In: FOUCAULT, Michel. Microfísica do Poder. São Paulo: Editora Graal, 2008.

FOX, Nick; WARD, Katie. Pharma in the bedroom...and the kitchen...The pharmaceuticalisation of daily life. Sociology of Health \& Illness, v.30, n. 6, 2008, p.856-868.

GIAMI, Alan. Da impotência à disfunção erétil. Destinos da medicalização da sexualidade. Physis, v. 3, n. 19, 2009, p.637-658.

HISLOP, Jenny; ARBER, Sara. Understanding women's sleep management: beyond medicalization-healthicization! Sociology of Health \& Illness, v. 25, n. 7, 2013, p. 815-837.

LATOUR, Bruno \& WOOLGAR, Steve. A vida de laboratório. A produção de fatos científicos. Rio de Janeiro: Relume Dumará, 1997.

LeBRETON, David. Antropologia do Corpo e Modernidade. Petrópolis: Editora Vozes, 2011.

LOE, Meika. Fixing broken masculinity: Viagra as a technology for the production of gender and sexuality. Sexuality and Culture, v. 3, n. 5, 2001, p.97-125.

MARSHALL, Barbara. Climateric redux?: (re)medicalizing the male menopause. Men and masculinity, n. 9, 2007, p.509-529.

MARSHALL, Barbara L. \& KATZ, Stephen. Forever functional: sexual fitness and the ageing male body. Body \& Society, v. 4, n. 8, 2002, p.43-70.

NUCCI, Marina Fischer. Seria a pílula anticoncepcional uma droga de "estilo de vida"? Ensaio sobre o atual processo de medicalização da sexualidade. Sexualidad, Saludy Sociedad, n. 10, 2012, p. 124-139.

OUDSHOORN, Nelly. Beyond the natural body: an archeology of sex hormones. Londres e New York: Routlegde, 1994. 
ROHDEN, Fabíola. Uma Ciência da Diferença: sexo e gênero na medicina da mulher. Rio de Janeiro: Editora FIOCRUZ, 2009.

ROHDEN, Fabíola. "O homem é mesmo a sua testosterona": promoção da andropausa e representações sobre sexualidade e envelhecimento no cenário brasileiro. Horizontes Antropológicos, v. 35, n. 17, 2011, p.161-196.

ROSE, Nikolas. A política da própria vida: biomedicina, poder e subjetividade no século XXI. São Paulo: Paulus, 2013.

ROSENBERG, Charles E. The Tyranny of Diagnosis: Specific Entities and Individual Experience. The Milbank Quarterly, v. 2, n. 80, 2002, p.237-260.

RUSSO, Jane; ROHDEN, Fabíola; TORRES, Igor \& FARO, Livi. 0 campo da Sexologia no Brasil: constituição e institucionalização. Physis, v. 3, n. 19, 2009, p. 617-636.

RUSSO, Jane; ROHDEN, Fabíola; TORRES, Igor; FARO, Livi; NUCCI, Marina; GIAMI, Alain. Sexualidade, Ciência e Profissão no Brasil. Rio de Janeiro: CEPESC, 2011.

RUSS0, Jane. A terceira onda sexológica: Medicina Sexual e farmacologização da sexualidade. Sexualidad, salud y sociedad, n.14, 2013, p.172-194.

TRAMONTANO, Lucas. “Continue a nadar": sobre testosterona, envelhecimento e masculinidade. Março de 2012. 128 f. Dissertação (Mestrado em Saúde Coletiva) - Instituto de Medicina Social, Universidade do Estado do Rio de Janeiro, Rio de Janeiro. 2012.

TRAMONTANO, Lucas. 0 Novo Homem Velho. Cabo dos Trabalbos, v. 10, 2014, p. $1-18$. 